\title{
Os materiais plásticos no acondicionamento dos géneros alimentícios
}

O acondicionamento dos géneros alimentícios tem conhecido, nas últimas décadas, um enorme desenvolvimento de forma a satisfazer as necessidades alimentares de populaçōes cada vez mais numerosas, com um intenso ritmo de vida e concentradas em cidades cada vez maiores.

Assegurar que os géneros alimentícios cheguem ao consumidor em perfeitas condições higiénicas, tenham uma duração tão longa quanto possível, permitam uma rápida e pronta aquisição em embalagens leves, fáceis de transportar e armazenar, são imperativos aos quais as indústrias ligadas ao sector têm dedicado o melhor dos seus esforços.

As embalagens destinadas ao contacto directo com géneros alimentícios, para além das qualidades exigidas a uma boa embalagem, deverão revelar-se inócuas em relação ao produto acondicionado e não lhes alterar as características organolépticas.

\section{As matérias plásticas e a embalagem}

No acondicionamento dos géneros alimentícios, aos materiais tradicionais vieram, nas últimas décadas, juntar-se os materiais plásticos. Não se pode dizer, na verdadeira acepção, que estes materiais os tenham vindo substituir, pois todos eles têm características próprias e aplicaçðes específicas. Todavia o aparecimento dos materiais plásticos, fruto da contínua inovação científica e tecnologica, veio originar uma profunda transformação no acondicionamento, armazenagem e distribuição dos géneros alimentícios. A grande diversidade de polímeros que é possível fabricar com distintas propriedades, permite escolher o mais adequado acondicionamento face às diferentes utilizaçб̃es. Podem-se obter materiais dos mais rígidos aos mais flexíveis, e conseguir que sejam tão leves como o papel, e de grande impermeabilidade aos gases, vapor de água e oxigénio.

De entre as várias propriedades dos materiais plásticos convém destacar algumas das que interessam ao sector do acondicionamento de géneros alimentícios:

- grande inércia química;

- densidade bastante baixa, obtendo-se embalagens leves, e em geral, pouco frágeis;

- facilidade de fecho por soldadura electrónica, termosoldadura ou outro sistema;

- barreira ao ar, humidade e luz, adequada a cada género alimentício, e que varia consoante o material plástico utilizado;

- alguns materiais suportam temperaturas requeridas para pasteurização ou esterilização, ou resistem a temperaturas muito baixas;

- boa apresentação da embalagem pela facilidade de impressão, coloração e decoração;
- possibilidade de obter as variadas formas normalmente requeridas pelos departamentos de marketing. Conforme as exigências do género alimentício algumas das características pedidas ao material de acondicionamento variam. Está neste caso a noção de impermeabilidade. É evidente que em relação a qualquer género alimentício o material deve ser impermeável aos microorganismos. Contudo, relativamente aos gases, vapor de água, luz e radiaçð̄es ultravioletas, observam-se diferentes exigências, como se exemplifica:

- carnes frescas, frutos e legumes frescos: necessitam de películas impermeáveis ao vapor de água de forma a evitar a desidratação, mas ligeiramente permeáveis aos gases para permitir trocas gasosas;

- matérias gordas: exigem películas impermeáveis ao oxigénio e aos raios ultravioletas para não favorecer a oxidação que conduziria à rancidez.

Frequentemente, por imperativos técnicos ou comerciais, recorre-se à conjugação de materiais de diferentes origens. As matérias plásticas são muito utilizadas como vernizes de protecção das embalagens metálicas, e na forma de película, combinam-se com outros materiais flexíveis, formando os denominados complexos, nos quais se adicionam as qualidades e se procuram eliminar os defeitos específicos de cada um.

\section{Compatibilidade com os géneros alimentícios}

Quando um género alimentício entra em contacto com um material de qualquer natureza, e exceptuando casos, como por exemplo de alimentos sólidos e secos, verifica-se uma interacção entre eles. Tem lugar uma absorção de constituintes do género alimentício pelo material e, fundamentalmente, uma migração dos constituintes do material para o género alimentício, o que pode originar problemas de ordem toxicolbgica ou organoléptica.

A inércia química total não existe. Todavia, em muitos casos ela é mínima e desprezável.

A possibilidade da migração causar ou não perigo para a saúde pública, modificar inaceitavelmente a composição dos géneros alimentícios, ou lhes alterar as características organolépticas, depende essencialmente da quantidade e do tipo de constituintes que migram para o género alimentício.

No caso concreto dos materiais plásticos, a sua compatibilidade com os géneros alimentícios assume uma enorme e complexa importância, dada a grande diversidade das resinas base e dos numerosos aditivos que, em geral, se adicionam a essas resinas. Assim, procurar-se-à observar um pouco mais detalhadamente os as-

\footnotetext{
anstituto de Qualidade Alimentar (IQA)
} 
pectos relacionados com a migração $\mathrm{e}$ a alteração dos caracteres organolépticos.

\subsection{Migração}

A resina base de uma matéria plástica é constituída por um polímero, em geral insolúvel, e que quando puro é quimicamente inerte. Quando a polimerização é bem conduzida as quantidades de monómero que ficam livres, e portanto susceptíveis de migrar, são extremamente diminutas. Obter uma boa polimerização deve ser uma preocupação constante dos industriais de forma a evitar a migração do monómero livre para o alimento com as resultantes possiveis modificaçðes organolépticas e, essencialmente, pelos seus prováveis efeitos toxicológicos. Está neste caso a presença do monómero cloreto de vinilo (VCM) no PVC, já objecto de restriçðes, quer a nível de muitos países, quer da própria Comunidade Europeia. Encontram-se publicadas algumas directivas da CEE visando em particular este monómero.

Geralmente à resina base adicionam-se determinados aditivos com o objectivo de que a matéria plástica adquira as características pretendidas. Estes aditivos que pertencem a diversas categorias (lubrificantes, estabilizantes, plastificantes...), são em geral substâncias de pequeno peso molecular que se podem deslocar no interior da matéria plástica, e dado que são muito reactivas, poderão causar interaç̧ð̃es com o género alimenticio ou solubilizar-se. Estas substâncias são, portanto, muito susceptíveis de migrar. Muitos países têm elaborado listas dos aditivos (e dos monómeros) autorizados na composição destinada ao contacto com géneros alimentícios (listas positivas), bem como limitam a migração (migração específica) de algumas dessas substâncias.

Também se tem procurado definir a quantidade máxima, do conjunto de todos os constituintes da matéria plástica, que podem migrar para o género alimentício (limite de migração global). Este valor, de carácter quantitativo, é de grande importância. Embora o material deva ser constituído somente por substâncias não tóxicas ou de pequena toxicidade, as quais nem sempre são, na totalidade, do conhecimento do fabricante da embalagem, nem de quem acondiciona o género alimentício, torna-se muito difícil detectar pequenas quantidades de constituintes específicos que migram. A migração global permite conhecer a quantidade de constituintes da embalagem que se podem encontrar presentes no género alimentício. $\mathrm{O}$ valor do limite de migração global não reúne ainda o consenso de todos os países da CEE. Numa proposta do Conselho da Europa (documento PSG/78-26 de Agosto de 1978 - Estrasburgo) é indicado para esse limite o valor de $60 \mathrm{mg} / \mathrm{kg}$ de alimento.

Além da composição da matéria plástica numerosos factores podem influenciar a migração: características dos géneros alimentícios, duração do contacto, temperatura, luz, relação entre o volume do género alimentício e a área de contacto, etc.

Apesar do que se referiu, e exceptuando um caso ou outro que entretanto possa surgir, não parecem importantes os problemas toxicologicos que se deparam neste sector. Têm-se realizado numerosos estudos e avaliado os riscos toxicológicos das diversas substâncias. Pode-se mesmo referir que os materiais plásticos se encontram melhor controlados do que outros materiais utilizados no acondicionamento de géneros alimentícios.

\subsection{Aspecto organoléptico}

Sendo evidente que o problema toxicológico predomina em relação aos materiais que são susceptíveis de entrar em contacto com géneros alimentícios, a preservação das qualidades destes, os quais se destinam a ser consumidos, assume também uma grande importância.

$\mathrm{Na}$ apreciação dos géneros alimentícios, o cheiro e o gosto são factores primordiais, os quais, conjuntamente com o aspecto, cor e consistência, constituem os caracteres organolépticos. Estes são fenómenos complexos e nem sempre susceptíveis de serem determinados objectivamente.

As eventuais modificaçð̃es dos caracteres organolépticos dos géneros alimentícios acondicionados podem ser de natureza físico-química ou química.

As alteraçðes de natureza físico-química estão intimamente relacionadas com a permeabilidade do material. Esta propriedade, que já foi referida, tem uma grande importância no acondicionamento dos géneros alimentícios. No caso das matérias plásticas, dada a grande diversidade de graus de permeabilidade aos vários factores (gases, aromas, vapores, luz...), e das diferentes exigências dos géneros alimentícios, ela deverá ser conscienciosamente aplicada, para não alterar de maneira inaceitável os respectivos caracteres organolépticos.

A natureza química das possíveis modificaçð̃es organolépticas dos géneros alimentícios acondicionados, está relacionada com as interacçð̌es entre a embalagem e o conteúdo.

Pode-se referir que um polimero puro e bem estabilizado, é geralmente inodoro. Contudo pequenas quantidades de monómeros livres podem comunicar gostos e sabores estranhos.

Também alguns aditivos utilizados no fabrico da matéria plástica, principalmente quando é requerida uma temperatura elevada, poderão contribuir para a modificação dos caracteres organolépticos.

Determinados géneros alimentícios, em particular substâncias gordas e bebidas alcoólicas, são muito susceptiveis de adquirir gostos e cheiros, por solubilizarem alguns tipos de aditivos e monómeros livres.

\section{Conclusão}

Os plásticos constituem no presente cerca dum terço do total dos materiais de embalagem.

As suas características permitem utilizá-los em variadas situaçðes, correspondendo a exigências específicas dos diferentes géneros alimentícios. Podem-se obter materiais extremamente flexíveis ou muito rigidos, opacos ou transparentes, com diferentes graus de permeabilidade a vapores, gases, aromas..., retrácteis ou estáveis termicamente, etc. Quando necessário, associam-se a outras matérias-primas ou entre si, conjugando diferentes propriedades.

Os materiais plásticos geralmente apresentam uma grande inércia química. Os estudos toxicológicos tentam acompanhar o desenvolvimento tecnológico, pelo que, por parte dos consumidores, não haverá que recear o aparecimento de situaçðes que possam fazer perigar a sua saúde.

Igualmente se encontram salvaguardados os caracteres organolépticos dos géneros alimentícios se o material que os acondiciona for adequado às suas características e se a migração for controlada, reduzindo-se ao mínimo o teor do monómero residual. 


\section{Referências bibliográficas}

- Brun Suzanne [editor] - Les matériaux en contact avec les aliments - Colloque National, Paris les 9, 10, 11 Février 1983. Ed. Technique et Documentation (Lavoisier).
- Lefaux, R. - Emballages et conditionnements d'aujourd'hui (Compagnie Française d'Editions, Paris 1967).

- Directiva 76/893/CEE de 23.11.76 - J.O. n. ${ }^{\circ} 1340$ de 9.12.76.

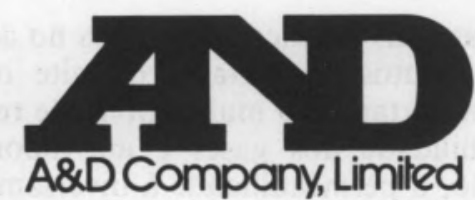

ER-I2OA D.2008X0.1mg

Analytical Balances ER-ASeries
ER-6OA

$60 \mathrm{~g} \times 0.1 \mathrm{mg}$

\section{REPRESENTANTES EXCLUSIVOS:}

VIARA COMERCIAL [MAQUINAS], LDA

SEDE: R.Delfim Ferreira, 509-4100 Porto

Tel. $683763-671351 / 2-\mathrm{tl} \times 26602$

FILIAL: Lisboa - tel. 804551/2

UMA GAMA COMPLETA DE

BALANÇAS ELECTRONICAS JAPONESAS:

* Analíticas

* De precisão lescala simples e dupla]

* De contagem

* Para pesagem de animais [até $2.000 \mathrm{~g}$ ]

* Para medição do teor de humidade

* Impressoras /Tratamento de dados

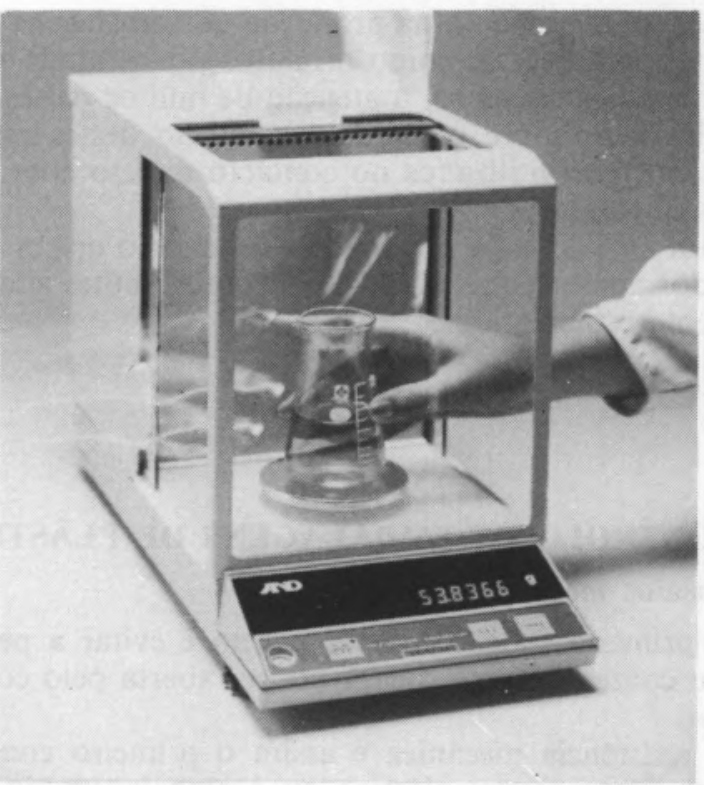

